\title{
Dispersal kernels and their drivers captured with a hydrodynamic model and spatial indices: A case study on anchovy (Engraulis encrasicolus) early life stages in the Bay of Biscay
}

\author{
M. Huret ${ }^{a}{ }^{\star}$, P. Petitgas ${ }^{a}$ and M. Woillez ${ }^{a}$
}

a IFREMER, Département Ecologie et modèles pour l'Halieutique, BP21105, 44311 Nantes, France

\author{
* Corresponding author : M. Huret, Tel.:+33 (0)2 403741 17; fax: +33 (0)2 403740 75, email address : \\ martin.huret@ifremer.fr
}

\begin{abstract}
:
Dispersal of fish early life stages explains part of the recruitment success, through interannual variability in spawning, transport and survival. Dispersal results from a complex interaction between physical and biological processes acting at different temporal and spatial scales, and at the individual or population level. In this paper we quantify the response of anchovy egg and larval dispersal in the Bay of Biscay to the following sources of variability: vertical larval behaviour, drift duration, adult spawning location and timing, and spatio-temporal variability in the hydrodynamics. We use simulations of Lagrangian trajectories in a 3-dimensional hydrodynamic model, as well as spatial indices describing different properties of the dispersal kernel: the mean transport (distance, direction), its variance, occupation of space by particles and their aggregation. We show that larval drift duration has a major impact on the dispersion at scales of not, vert, similar100 km, but that vertical behaviour becomes dominant reducing dispersion at scales of not, vert, similar1-10 km. Spawning location plays a major role in explaining connectivity patterns, in conjunction with spawning temporal variability. Interannual variability in the circulation dominates over seasonal variability. However, seasonal patterns become predominant for coastal spawning locations, revealing a recurrent shift in the direction of dispersal during the anchovy spawning season.
\end{abstract}

\section{Introduction}

Dispersal of early life stages is a key process in the life cycle of most marine populations. It has implications on the structure and dynamics of populations, as well as the persistence, evolution and distribution of species through connectivity processes ([Gaines et al., 2007] and Cowen and Sponaugle, 2009 R.K. Cowen and S. Sponaugle, Larval dispersal and marine population connectivity, Annual Review of Marine Science 1 (2009), pp. 443-466. Full Text via CrossRef[Cowen and Sponaugle, 2009]). In fisheries science, it has been recognized for almost a century now that it also explains a large part of the recruitment variability ([Hjort, 1914] and [Sinclair, 1988]). Recent modelling studies give evidence that physical processes leading to larval retention or dispersal significantly influence the recruitment success of fish, for example cod and sprat in the Baltic Sea ([Hinrichsen et al., 2002] and [Baumann et al., 2006]) or cod and haddock on Georges Bank (Lough et al., 2006).

Coupled physical-biological models of early life stages received major attention during the past 20 years ([Werner et al., 2001], [Werner et al., 2007] and [Gallego et al., 2007]) because they have the ability of integrating all processes and 
scales involved in larval dispersal, from regional circulation to small scale physics, with potentially individual behaviour, growth and survival. These features make models into comprehensive tools of investigation and potentially prediction (Miller, 2007; Svendsen et al., 2007). Most of these models are Individual Based Models (IBMs) in which particles are tracked within a hydrodynamic 3D field.

Description of particle distribution along the drift has been assessed in relation to specific processes related to enrichment, concentration or retention (e.g. Lett et al., 2006), the three components of Bakun's triad (Bakun, 1996), or by measuring the transport success depending on suitable nursery areas (Huggett et al., 2003; Huret et al., 2007; Edwards et al., 2008; Parada et al., 2008). For pelagic species that do not have specific geographic areas for settlement, defining transport success areas may be seen as a rather arbitrary task. A more comprehensive description of the distribution of particles has been proposed with the dispersal kernel (Nathan and Muller-Landau, 2000), i.e. the probability density function of particles as a function of the distance from release location. This was first assessed in one dimension (e.g. Siegel et al., 2003), but Edwards et al. (2007) extended the definition in two dimensions by completing the set of indices to better describe the kernel in areas with strong anisotropy of the circulation, which is often the case in coastal areas. Here, we complement this approach by adding spatial indices related to spatial occupation and aggregation.

In this paper, using a Lagrangian particle tracking model and these spa- 
tial indices describing the dispersal kernel, we assessed the sensitivity of the dispersal of anchovy early life stages to several factors of variability. We follow an approach first proposed by Huggett et al. (2003), in which we define numerical experiments, indices characterising biological patterns (here the dispersal kernel), and use a statistical analysis to sort and quantify the effects of the selected factors. Variability in dispersal of early life stages results from a wide range of oceanographic processes (Werner et al., 1997; Pineda et al., 2007), from large-scale forcing of regional circulation, to mesoscale processes (e.g. river plumes, upwellings, eddies) and finally to small scale interactions of physical and biological processes (e.g. turbulence and biological behaviour). These different sources of variability likely impact larval dispersal in the Bay of Biscay.

The Bay of Biscay is an open oceanic bay located at mid-latitude, with a large shelf $(150-200 \mathrm{~km})$ along the French coast north of $45^{\circ} \mathrm{N}$, narrowing southward to reach only a few tens of kilometers along the Spanish coast (Fig. 1). Tidal components remain relatively low in the bay, with increasing importance from south to north (Le Cann, 1990), and a potential effect on vertical mixing of planktonic particles, especially along the coast. The residual circulation over the French continental shelf is generally weak and runs north-westward (Pingree and Le Cann, 1989), with strong seasonal variability due to wind and runoff from major rivers (Loire, Gironde and Adour). During winter, prevailing winds are from the southwest and during periods of high river runoff plumes spread usually northward and alongshore (Puillat et al., 2004). When the river discharge decreases and winds are mainly from 
the northwest, plumes are driven offshore or southward. Figure 1 illustrates this shift in the surface currents for the year 2008, with northward buoy trajectories from April releases and weak southward drift from June releases.

In addition to this seasonal and interannual variability of the circulation, we also tested the sensitivity of the dispersal to population traits, i.e. timing and location of spawning. The former is relatively well captured in our hydrodynamic model, while the latter is well described in the literature. However, large uncertainties remain on larval drift duration during which transport may be considered as passive. This duration depends on development rates and associated acquisition of swimming capacities. Dispersal was also demonstrated to be highly sensitive to vertical distribution in the water column (Huret et al., 2007; North et al., 2008). Based on these uncertainties, we included drift duration and vertical behaviour in our analysis to discuss their potential implication on the dispersal kernel. Because our objective in this paper is not to comprehensively predict survival, no consideration was made of complex biological processes interacting with the environment, such as growth and predation. Also we made the choice for our sensitivity analysis of testing and analysing the selected factors independently, that is without any ontogenetic change for larval vertical behaviour, so that their respective effects on the dispersal can be quantified. 


\section{Methods}

\subsection{The hydrodynamic model.}

The model MARS (hydrodynamic Model for Application at Regional Scale) was set up for the Bay of Biscay area (Lazure and Dumas, 2008; Lazure et al., 2009). The geographic domain of the 3D model extends from $43.2^{\circ} \mathrm{N}$ to $50.8^{\circ} \mathrm{N}$, and from $8^{\circ} \mathrm{W}$ to $0.4^{\circ} \mathrm{W}$, covering the whole Bay of Biscay and the western English Channel. The model grid has $4 \mathrm{~km}$ resolution on the horizontal, with 30 sigma layers on the vertical. A $2 \mathrm{D}$ model is run over a larger area (from Portugal to Norway) to provide surface elevation to the 3D model boundaries. Tidal components along the open boundary of the large model were extracted from FES2004 (Lyard et al., 2006).

Atmospheric forcing (wind fields, air temperature, atmospheric pressure, cloud cover and relative humidity) are provided by the Météo-France model ARPEGE with $0.5^{\circ}$ resolution over the Bay of Biscay. Bulk formulae are used for heat flux calculations. Daily river discharges from the Loire, Gironde, Adour et Vilaine rivers are included. Boundary conditions for temperature and salinity are provided by the Reynaud climatology (Reynaud et al., 1998). This configuration of MARS was validated for hydrology over the continental shelf over the years 1999-2004 (Lazure et al., 2009). For our study, years from 1996 to 2007 were run, using outputs from a long term hindcast as initial conditions. 


\subsection{Particle tracking module.}

A particle tracking module is run online on the same adaptive time-step as the hydrodynamic model (i.e. between 300 and 900s). This allows for resolution of the tide. It is based on the explicit Runge-Kutta scheme. Velocities are lineraly interpolated from the 3D model grid. In addition to the $3 \mathrm{D}$ advection, we use a random walk process in the vertical to describe diffusion of particles affected by turbulence. The latter is mainly due to wind, but also tide in shallow areas of the bay. The calculation of the random walk is based on the model-computed eddy diffusivity following Visser (1997), with the time step criterion given by Ross and Sharples (2004) to avoid accumulation at the bottom and surface boundaries. The resulting time step we chose for the random walk process is $1 / 100$ of the model time step.

\subsection{Definition of experiments.}

Particle tracking experiments were performed for every year between 1996 and 2007 from a total of 18 release dates, one every week from beginning of April to end of July. In addition to spawning dates, we also tested 5 discrete spawning locations (circled areas with a 40km diameter, see Fig. 1). These match with known spawning areas, but at various times of the year. Indeed, the south-eastern Bay of Biscay forms a recurrent and intense spawning area for anchovy, but as the season progresses spawning is also known to move up north and west (Motos et al., 1996). Intense spawning is observed at southern locations during the IFREMER's acoustic and egg survey PELGAS in May. However, in 2003, in addition to high water temperatures, the survey was delayed to June, and significant concentrations of eggs were observed in the 
northern part of the Bay. We then selected three southern locations $(1,2,3)$, representative of the most intense spawning, and two other locations north of the Gironde estuary (4 and 5), representative of later and more episodic spawning. Three of these locations are associated with plumes, offshore of the Adour, the Gironde and the Loire estuaries. Two other locations are associated with relatively more oceanic waters, in the vicinity of the shelf break and consequently potentially associated to slope eddies (Pingree and Le Cann, 1992).

In addition to characterizing spatio-temporal patterns of variability, we tested factors associated with anchovy biology and development, that may influence the dispersal kernel. The first one is egg and larval drift duration. We consider age at metamorphosis as the limit before horizontal swimming may become significant as compared to transport by currents. There is some evidence that individuals as small as $15 \mathrm{~mm}$ Standard Length (SL) aggregate at small scales (Cotano et al., 2008), but there is no evidence for a directed horizontal behaviour at larger scales. Ré (1996) estimated metamorphosis, from larval growth studies in the laboratory, at an age of approximately 60 days for a SL of 35-40 mm. In the Adriatic Sea, La Mesa et al. (2009) give a range of 30-50 days for a Total Length of $40.7 \mathrm{~mm}$ at metamorphosis. For our sensitivity analysis we allow the passive drift duration to vary between 20 and 70 days, which is 10 days earlier (at the lower limit) and 10 days later (at the upper limit) than the range resulting from our literature survey. The second biological factor is vertical swimming behaviour, for which we tested three configurations : (i) drift at fixed vertical depth, (ii) random 
walk alone with turbulence affecting passive particles as detailed earlier, and (iii) diel vertical migration in addition to random walk, with upward swimming $\left(1 \mathrm{~cm} . \mathrm{s}^{-1}\right)$ at dusk and directed to a depth of $20 \mathrm{~m}$ at dawn. These configurations are not realistic since turbulence affects eggs in any case and larval vertical behaviour evolves through ontogeny. However, as in Edwards et al. (2007) or Parada et al. (2008), we make the choice for our sensitivity study to fix the tested factors for a more robust assessment of their respective effects. In our experiments, particles are released from the surface to $25 \mathrm{~m}$, that is above the seasonal thermocline (Puillat et al., 2004), and every five meters.

Our experiment plan, detailed in Table 1, tests all combinations of factors for a total of 19440 model simulations, with 1575 particles released for each one of them. This configuration of a full experiment plan provides straightforward interpretation of the results.

\subsection{Capturing the dispersal kernel.}

The term dispersal kernel usually refers to the probability density function relating particle distribution to distance from a release or spawning location. Following Edwards et al. (2007) we extend this definition in two dimensions, allowing for anisotropy in the regional circulation, hence in the transport and final distribution of the particles to be captured.

The spatial patterns of the particle distributions can be quantified using spatial indices (Woillez et al., 2009). The centre of gravity (CG) charac- 
terises the mean location of the particles. Geographic position (Latitude and Longitude) represent the absolute position of the CG, whereas distance and direction from the release position (i.e. CG of the distribution before the drift) is related to the mean relative transport, independently of the geographic position of the spawning areas. Inertia characterises the dispersion or variance around the CG. Inertia is not identical in every direction of space, and can be decomposed into its two principal axis, orthogonal to each other, explaining, respectively, the maximum (Imax) and the minimum (Imin) parts of overall inertia. This is provided by a principal component analysis of the position of particles and the resulting axes can be represented in space as an ellipse. The characteristics of this ellipse, such as the length $(\sqrt{\operatorname{Imax}})$ and the orientation of the major axis, the length of the minor axis $(\sqrt{\operatorname{Imin}})$, and the isotropy $\left(\sqrt{\frac{I \min }{I \max }}\right)$ are used in addition to the CG and Inertia for a more complete description of particle distribution.

For a given inertia, the distribution of particles may display a variety of patterns related to dispersion at smaller scales, depending on the occupation of space, from homogeneous density distribution to strong aggregations. These patterns may arise from oceanographic processes (e.g. eddies concentrating or dispersing particles), or biological processes such as behaviour, concentrating particles in a particular vertical layer which in turn limits particle dispersion in the horizontal. To describe these aspects of the spatial patterns we used indices developed in Woillez et al. (2009) to capture spatial patterns of adult fish populations. In our case, we derive the density of particles ( $\mathrm{d}$ in number per $\mathrm{km}^{2}$ ) over the whole model domain on a spatial 
grid of $5 \mathrm{~km}$ resolution (unit surface $\mathrm{S}=5 \mathrm{~km}^{2}$ ). The indices we considered are as follows. The positive area (PA), which is the sum of area units containing at least one particle. The PA is highly sensitive to low density values that have the same contribution as high density values. The spreading area (SA), which is a measure of how the densities are distributed within the PA. If $\mathrm{A}$ is the cumulated area occupied by the density values, ranked in decreasing order, $\mathrm{Q}(\mathrm{A})$ the corresponding cumulated abundance, and $\mathrm{Q}$ the overall abundance, then the SA is defined as twice the area below the curve expressing $(Q-Q(A)) / Q$ as a function of $\mathrm{A}$ :

$$
S A=2 \int \frac{(Q-Q(A))}{Q} d A
$$

The SA is much less sensitive to low values of density than is the PA.

The equivalent area (EA) measures the inverse of the probability that two particles chosen randomly are in the same grid cell, and so its inverse can be considered as an index of aggregation. It is defined as :

$$
E A=\frac{S *\left(\sum_{i} d_{i}\right)^{2}}{\sum_{i} d_{i}^{2}}
$$

for each cell $\mathrm{i}$, with density of particles $d_{i}$, of the model domain. Being particle-based, the EA is very sensitive to the highest density values. SA and EA equal PA when particles are evenly spread at constant density.

The last index is the coefficient of variation of positive values of densities $\left(\mathrm{CV}_{0}\right)$ and is used to characterise the statistical dispersion of density of particles. Finally, the set of 13 indices summarised in Table 1 is used to quantify the effects of the different factors on the dispersal kernel. 


\subsection{Statistical analysis.}

In addition to simple statistics and descriptive illustrations, our analysis proceeds with two main statistical steps. We first perform a multi-factor, multi-variable analysis of variance (MANOVA) to evaluate impacts on kernel indices of the various factors : release date, release location, drift duration and vertical behaviour. We use the 50-50 MANOVA R code from Langsrud (2002) which handles multiple highly colinear responses, and 4 sets of response variables are tested : (i) the geographic position of the CG, (ii) indices of the mean relative transport (distance and direction of the CG from the release location), (iii) the ellipse characteristics (Inertia, $\sqrt{\operatorname{Imin}}, \sqrt{\operatorname{Imax}}$, Isotropy, Orientation of major axis), and (iv) indices of space occupation and aggregation (PA, SA, EA and $\mathrm{CV}_{0}$ ).

In the second step we perform a Multiple Factor Analysis (MFA, Escofier and Pagès (1994)), to evaluate the reproducibility across years of correlation between indices and allows separation of the variability among seasons and years. Woillez et al. (2007) used this method on adult fish survey data, to study the persistence through time of spatial patterns characterizing the distribution of different age groups. In our case, the dispersal kernel of a whole spawning season can be considered as a combination of the kernel of each of its spawning dates, allowing for some differences (or shifts) between them. The hydrological conditions for each release date, which may be fairly similar from year to year, result in specific spatial features for each kernel. A persistent relationship between each release date is expected, with some interannual variability. The MFA was performed using $\mathrm{R}$ package ade4 (Dray 
and Dufour, 2007). MFA provides a simultaneous representation of the 18 release dates for the 12 simulated years, based on the whole set of indices except geographic position. For this analysis, we consider spawning locations separately, in the model configuration with vertical migration for particles and for a passive drift duration of 50 days.

\section{Results}

\subsection{Quantifying effects on the kernel.}

Principal Component Analysis (PCA) on index values from all experiments indicates which indices best describe variability between dispersal kernels (Fig. 2). The first component discriminates between distributions of particles with high and low inertia (inertia and length of principal axis), and between large and small positive area. The second component separates high from low $\mathrm{CV}_{0}$ kernels. Vertical behaviour is the best discriminating factor from the analysis. When compared to a fixed vertical position, a vertical random walk process has the effect of increasing the local dispersion of particles (higher areas) with no apparent change in the inertia, while decreasing the $\mathrm{CV}_{0}$ of the densities (see Fig. 3 as an example). Adding a vertical swimming behaviour has the opposite effect, even if a random walk is included in this process configuration.

MANOVA helps rank the effects of different factors, as well as the effects of their interactions. Considering the whole set of indices, we verify that behaviour is the factor explaining the most important part $(18.9 \%)$ of the 
dispersal kernel variability (see Table 2). Spawning location explains almost the same variance $(17 \%)$ and drift duration explains $12.3 \%$. The effect of timing of spawning (both week and year) is low, but becomes more significant in interaction with location, and there is also a significant interaction effect between season and year on the mean drift distance and direction (6.5\%). Looking at the different set of indices separately, we see that different factors have impacts on different properties of the kernel. Geographic position of the centre of gravity of the distributions is mostly explained by the location of spawning itself $(62.4 \%)$, or in interaction with temporal variability of spawning. Relative transport with respect to release location is also mostly explained by spawning location itself, with interaction effects due to timing of spawning. Characteristics of the dispersal ellipse are explained (almost $20 \%$ ) by the drift duration, with some interannual variability. Finally, aggregation patterns, as seen with the PCA, are mostly affected by the vertical behaviour of particles (55.4\%), and then by drift duration (11\%).

\subsection{Impact of larval drift duration.}

Fig.4 shows that several indices increase almost linearly with increasing drift duration. This is the case for inertia, distance (from 75 to $150 \mathrm{~km}$ between 20 and 70 days), and positive area. Increasing rate of the equivalent area is higher, thus lower for the $\mathrm{CV}_{0}$ through the following relationship : $P A / E A=1+C V_{0}^{2}$ (Woillez et al., 2007). When $\mathrm{CV}_{0}$ levels out while PA and EA increase it means that the total dispersion envelope increases whereas small agregations of particles are maintained. The temporal variability for these indices also progressively increases, revealing lower stability of the dis- 
persal kernel over time when drift duration increases, except for the direction which shows relatively more stability.

\subsection{Spatial variability of the dispersal.}

As seen with the MANOVA, spawning location is the main factor of variability of the geographic position of the CGs. Less expectedly, it also explains the main part of the mean relative transport (i.e. distance and direction), revealing higher spatial variability in the circulation, in reference to the release position, than temporal variability. Fig. 5 indicates a larger dispersal distance for coastal spawning locations 1, 3 and 5 (respectively 173, 120 and $137 \mathrm{~km}$ ) with also higher temporal variability especially for spawning offshore of the Adour and Loire estuaries (1 and 5). Mean drift direction is shifted south when spawning is progressing northward (see locations 1, 3 and 5 of Fig. 5). This is partly explained by the coastline configuration, constraining particles to drift west rather than south along spanish coast, which occurs more often for southern spawning locations. Isotropy of the ellipse is also much higher for spawning location 1, apparently more affected by offshore isotropic circulation than shelf circulation, or because drift in both north and west direction give two equivalent axes of dispersion. There seems to be higher temporal variability in the direction for offshore spawning locations 2 and 4. The principal axis of a PCA computed on positions of CGs of the kernels are plotted in Fig. 6, together with the mean trajectories for each spawning location. It shows a general offshore drift from all locations, which is larger for southern coastal ones (1 and 3). Distribution of the CGs has an along shelf orientation (major axis), which is less obvious from locations 1 
and 4. Highest isotropy is for CGs of spawning location 1 (as for the dispersal kernel themselves), which again may be explained by the change in coastline orientation as well as a greater influence of offshore circulation.

\subsection{Seasonal variability of the dispersal.}

Temporal effects (both annual and seasonal) are relatively low on the dispersal kernel when compared to other factors (Table 2). This is partly due to the large spawning location effect that interacts significantly with the factors week and year, especially for the set of indices related to location and ellipse. This suggests that temporal response of the dispersal kernel may vary spatially. Fig. 7 describes the evolution of the mean drift along the season. For coastal spawning locations, there is a shift from a northward to southward (westward for location 1) direction. There is no clear signal for locations 2 and 4, meaning higher interannual variability. Indeed, when looking at the coastal locations only $(1,3,5)$, the respective effects equilibrate and even reverse when looking at the relative location set of indices $(6.6 \%$ and $8 \%$ of explained variability for year and week effects, respectively). Focusing on major spawning location 3 (Fig. 8), we note that the reversal in the mean drift direction occurs for releases around May, with a slight increase of the distance over which the CGs are transported, and a large increase of inertia around the CGs.

The MFA approach is used to give an overview of the relationship between the different spatial indices and to assess their persistence through time for each spawning location individually. The first two axes of the MFA 
accounted for $39 \%, 32 \%, 42 \%, 31 \%$ and $41 \%$ for locations 1 to 5 respectively and for a larval drift duration of 50 days. As already seen in Fig. 7 for distance and direction, there is less reproducibility of spatial patterns among corresponding release dates from year to year for offshore spawning locations 2 and 4 . When performing the same analysis with a drift duration of 20 days, the first two axes of the MFA accounted for 46\%, 30\%, 34\%, $25 \%$ and $29 \%$ for locations 1 to 5 , respectively. This reveals the increasing stability of the seasonal dispersal pattern for increased larval drift duration, except for location 1.

The first axis of the MFA provides a good representation of the seasonal change of the dispersal kernel. The correlation between the indices and the axis are summarized in Table 3 for a larval drift duration of 50 days. Only spawning location 2 has the length of the maximum axis well correlated with a principal axis of order $>1$. For spawning location 1, indices related to inertia (Inertia and length of principal axis), mean drift (distance and direction) and positive and spreading areas are positively correlated to the first axis. For spawning location 2, positive and spreading area are positively correlated with the first axis. For spawning location 3, inertia indices, mean drift direction, positive and spreading areas are positively correlated with the first axis. For spawning location 5, mean drift direction is highly correlated whereas isotropy, distance, and area indices are negatively correlated with the first axis.

The seasonal evolution with respect to spatial features synthesized by 
the MFA is summarized in Fig. 9. As seen by comparison with Table 3, there are no clear seasonal patterns in the factorial space for locations 2 and 4. MFA for spawning location 1 (bottom) shows a progressive evolution along the first principal axis, until mid-June (week 10-11) with increasing direction of drift (to the west), higher dispersal distance, higher inertia and spatial coverage. After June, the dispersal pattern becomes stable. Spawning location 3 shows a progression over the whole spawning season along the first axis, corresponding to an increasing direction (from north to south), and increasing inertia and are covered. Spawning location 5 (top) is separated into two main groups of release dates along the first axis, the beginning of the season (releases 1 to 5 corresponding to April), with higher isotropy, higher distance, higher occupied areas than the end of the season. It reveals the observed shift in the direction from north to south. Fig. 9 also shows the seasonal evolution of interannual variability (or inertia in right panels), i.e. a pattern will be more stable over years when variability is low. This variability is higher for the first group of release dates (April) for location 5, increases toward the end of the spawning season for location 3, and shows a noisy negative trend for location 1.

\section{Discussion}

\subsection{Summary of the methodology.}

Our methodology was made of the following steps: setup of an experimental plan for model simulations considering all the investigated factors, choice of indices to characterise the dispersal kernel, and statistical analyse with MANOVA to identify the important factors of variability and MFA to 
separate between seasonal and interannual variability. As compared to a simple average transport calculation, our dispersal kernel is the result of all the variability in the transport along the simulated trajectories resulting from high frequency and mesoscale features occuring in the Bay of Biscay. Also the defined indices allow for properties such as dispersion at relatively large and small scales to be captured. Each factor of variability translates into different properties of the kernel, with underlying ecological consequences.

\subsection{Matching of spawning windows with retentive dispersal kernel.}

In the Bay of Biscay, interannual variability in the meteorological forcing is high, partially masking the seasonal patterns of circulation arising from shifts in wind direction and decrease of river runoff (Koutsikopoulos and Le Cann, 1996; Puillat et al., 2004) during anchovy peak spawning season in May-June (Motos et al., 1996). However, the seasonal pattern of dispersal is more stable for spawning along the coast in the river plumes, for which there is a clear shift in the drift direction within the anchovy spawning season. The seasonal pattern is also more visible for longer drift durations (except for location 1), because then residual circulation takes over short time scale variability. This seasonal shift was evidenced over the shelf with drogued buoys in 2008 (Fig. 1). Considering the northern shift of the spawning along the season (Motos et al., 1996), the seasonal shift in the drift direction would imply higher retention within the Bay of Biscay. Indeed, Adour spawning (location 1 of Fig. 6) with a north-nortwestward drift early in the season (Fig. 7) will retain particles in the proximity of the French shelf, as will a southern drift from Loire plume spawning (location 5) later in the season 
(Fig. 7). Conversely, later spawning in the south would imply larger dispersion to offshore areas, while earlier spawning in the north could seed the English Channel with larvae originating from the Loire plume (see Fig.10). Comparable modelling work on invertebrate larval dispersal and connectivity (Ayata et al., this issue) confirmed possible larval exchanges from the northern Bay of Biscay populations to the western English Channel populations, and Kelly-Gerreyn et al. (2006) reported low salinity water intrusions in the English Channel from the coastal Bay of Biscay plume in early spring in three consecutive years (2002-2004). The observed space-time spawning pattern for anchovy in the Bay of Biscay may well be a response to the seasonal shift in the dispersal kernel, corresponding to a space-time retentive spawning window.

As the spawning season progresses, mean drift distance (Adour plume, location 1) and inertia increases (Adour and Gironde plumes, locations 1 and 3), and also the dispersal pattern become less stable among years for the Gironde location (Fig. 9). This could be unfavorable for retention close to the shelf area where juveniles return later in the season (Irigoien et al., 2008). In the meantime, drift duration, which is highly dependent on growth rate, will decrease under the influence of increasing surface temperature, balancing the larger dispersal distance effect.

Spawning location has a dominant effect on mean locations (CGs) of ending positions of particles. However, the dispersal kernel analysis also shows that the spawning strategy not only favours retention but also ensures mix- 
ing of the progeny seeded on the various spawning grounds.

\subsection{Influence of the vertical behaviour.}

Edwards et al. (2007) defined a set of indices related to the mean position and variance of the particles. They showed that larval behaviour does not have a significant impact on the kernel, at least on the inner and mid-shelf off the US Southeast coast. By completing their set of indices with new indices related to the area coverage and statistical dispersion of the particle densities, we show that behaviour may be a major source of variability with vertical swimming resulting in higher aggregation of particles for a reduced occupied area. In the Bay of Biscay, the new indices (EA, SA, CV $\mathrm{CV}_{0}$ ) then characterise dispersion at smaller scales $(\sim 1-10 \mathrm{~km})$ than captured by inertia $(\sim 100 \mathrm{~km})$. For the southern Benguela ecosystem, Parada et al. (2008) showed that diel vertical migration could also result in differences at larger scales in the dispersal patterns, enhancing transport to the outer part of the known nursery areas, while drifting at a fixed depth would retain particles closer to their release areas. In our case, the small scale patterns detected may also be significant for transport success, with higher aggregation leading to a higher chance of encounter between individuals thereby achieving schooling.

Edwards et al. (2007) also analysed the effect of the horizontal dispersion coefficient used in the particle tracking model, showing a major influence on the variance or inertia around the mean position of the distribution. No horizontal dispersion was applied in our model, however, adding random walk 
in the vertical has the effect of dispersing particles in the horizontal. But the effect of vertical behaviour on the inertia is not obvious in our study. The reason for this difference may come from the use by Edwards et al. (2007) of a monthly mean flow field for particle tracking, filtering the variability of the circulation on scales of days to weeks, which has the effect of reducing the general dispersion of particles (Huret et al., 2007). The use of high temporal and spatial resolution for our model of the Bay of Biscay increases dispersal at scales measured by inertia, whatever the vertical process (and probably horizontal diffusion) configured. Adding horizontal diffusion would certainly result in lower aggregation at smaller scales, lower $\mathrm{CV}_{0}$ and higher surface occupied.

\subsection{Future developments.}

Dispersal kernels obtained for slope-associated spawning (locations 2 and 4 of Fig. 1) have to be considered with caution. Complex oceanographic processes occuring at the shelf break such as slope instabilities (Serpette et al., 2006), as well as large scale variability through the intrusion of the poleward slope current (Pingree and Le Cann, 1990; Garcia-Soto et al., 2002), are features weakly resolved in our regional hydrodynamic models. Their impacts will be assessed with future versions of our model that will better integrate these processes.

Our choice for simplified vertical behaviour in this study was made for sensitivity purposes. We showed the strong effect of this process on particle aggregation, and as such it deserves further research. To refine the disper- 
sal kernel in a more realistic modelling approach, explicit representation of egg buoyancy (Goarant et al., 2007), followed by a progressive acquisition of behavioural capacities at the larval stage allowing interaction with external forcing (Fiksen et al., 2007), will be an improvement. We also showed high sensitivity of the dispersal kernel to larval drift duration, a process dependent on development rate. As such, another necessary step is the integration of growth processes explicitly into IBMs (e.g. Lough et al., 2005), through the coupling to lower trophic level models (e.g. Daewel et al., 2008). Highly dependent on growth, mortality may also have a large impact on the resulting dispersal kernel by removing larvae drifting through unfavourable areas with low growth and/or high predation. Also, the choice was made in our study not to consider the influence of hydrology or bottom substrate along the trajectories that could influence larval behaviour and in turn modify the dispersal kernel. This is justified for pelagic species, since even if one can not rule out changes in swimming behaviour for better retention in favourable nursery areas, this process is far less obvious than for other fish species which actively select their settlement areas when they dwell over suitable bottom substrate. Finally, the strong dependency of dispersal on spawning location identified the need for full life cycle models which include the dynamics of spawning. These proposed developments of the IBM will extend the work by Allain et al. (2007) and allow hypothesis testing of the main drivers of anchovy recruitment in the Bay of Biscay (e.g. Irigoien et al., 2007). 


\subsection{Further utilisations of the dispersal kernel.}

Beyond our sensitivity analyse, we propose several applications using our dispersal kernel indices. First, they could be used in the design of research or operational surveys targeting early life stages, as assessed with juveniles in autumn in the Bay of Biscay to derive an abundance index. Second, for management or conservation purposes, seasonal and spatial variability of the dispersal kernel have large potential implications for the design of Marine Protected Areas (Fogarty and Botsford, 2007). Last, our study confirms that dispersal kernels result from the interaction between spawning location and timing, larval behaviour and properties of flow fields. Climate change may impact each of these components and therefore significantly modify the dispersal in ways that are beginning to be investigated (Lett et al., this issue). The methodology proposed here (drift simulations and biophysical model in general, indices and statistical analyses) may be useful in evaluating the impact of climate change scenarios on the dispersal of early life stages.

Aknowledgements. We aknowledge V. Garnier, F. Dumas and P. Lazure for MARS model development and original version of the associated Lagrangian module. We thank P. Fréon and an anonymous reviewer for their useful comments. This study was carried out with support from the European Commission through the projects RECLAIM ("Resolving Climate Impact on fish stocks", FP6 - Contract 044133) and UNCOVER ("Understanding the mechanisms of stock recovery", FP6 - Contract 022717). 


\section{References}

Allain, G., Petitgas, P., Lazure, P., 2007. The influence of environment and spawning distribution on the survival of anchovy (Engraulis encrasicolus) larvae in the Bay of Biscay (NE Atlantic) investigated by biophysical simulations. Fisheries Oceanography 16 (6), 506-514.

Ayata, S., Lazure, P., Thibaut., E., Submitted. How does the connectivity between populations mediate range limits of marine invertebrates ? a case study in the NE Atlantic. Progress in Oceanography. This issue.

Bakun, A., 1996. Patterns in the Ocean. Ocean processes and Marine Population Dynamics. San Diego, CA, USA: University of California Sea Grant, in cooperation with Centro de Investigaciones Biologicas de Noroeste La Paz, Baja California Sur, Mexico, 323pp.

Baumann, H., Grohsler, T., Kornilovs, G., Makarchouk, A., Feldmann, V., Temming, A., 2006. Temperature-induced regional and temporal growth differences in Baltic young-of-the-year sprat Sprattus sprattus. Marine Ecology Progress Series 317, 225-236.

Cotano, U., Irigoien, X., Etxebeste, E., Alvarez, P., Zarauz, L., Mader, J., Ferrer, L., 2008. Distribution, growth and survival of anchovy larvae (Engraulis encrasicolus 1.) in relation to hydrodynamic and trophic environment in the Bay of Biscay. Journal of Plankton Research 30 (4), 467-481.

Cowen, R. K., Sponaugle, S., 2009. Larval dispersal and marine population connectivity. Annual Review of Marine Science 1, 443-466. 
Daewel, U., Peck, M. A., Kuhn, W., St John, M. A., Alekseeva, I., Schrum, C., 2008. Coupling ecosystem and individual-based models to simulate the influence of environmental variability on potential growth and survival of larval sprat (Sprattus sprattus 1.) in the North Sea. Fisheries Oceanography 17 (5), 333-351.

Dray, S., Dufour, A.-B., 2007. The ade4 package: Implementing the duality diagram for ecologists. Journal of Statistical Software 22(4), 1-20.

Edwards, K., Hare, J., Werner, F., Seim, H., 2007. Using 2-dimensional dispersal kernels to identify the dominant influences on larval dispersal on continental shelves. Marine Ecology Progress Series 352, 77-87.

Edwards, K. P., Hare, J. A., Werner, F. E., 2008. Dispersal of black sea bass (Centropristis striata) larvae on the southeast US continental shelf: results of a coupled vertical larval behavior - 3D circulation model. Fisheries Oceanography 17 (4), 299-315.

Escofier, B., Pagès, J., 1994. Multiple factor analysis (afmult package). Computational Statistics and Data Analysis 18, 121-140.

Fiksen, O., Jorgensen, C., Kristiansen, T., Vikebo, F., Huse, G., 2007. Linking behavioural ecology and oceanography: larval behaviour determines growth, mortality and dispersal. Marine Ecology Progress Series 347, 195205.

Fogarty, M. J., Botsford, L. W., 2007. Population connectivity and spatial management of marine fisheries. Oceanography 20 (3), 112-123. 
Gaines, S. D., Gaylord, B., Gerber, L. R., Hastings, A., Kinlan, B. P., 2007. Connecting places. The ecological consequences of dispersal in the sea. Oceanography 20 (3), 90-99.

Gallego, A., North, E. W., Petitgas, P., 2007. Introduction: status and future of modelling physical-biological interactions during the early life of fishes. Marine Ecology Progress Series 347, 122-126.

Garcia-Soto, C., Pingree, R. D., Valdes, L., 2002. Navidad development in the southern Bay of Biscay: Climate change and swoddy structure from remote sensing and in situ measurements. Journal of Geophysical ResearchOceans 107 (C8), 3118.

Goarant, A., Petitgas, P., Bourriau, P., 2007. Anchovy (Engraulis encrasicolus) egg density measurements in the Bay of Biscay: evidence for the spatial variation in egg density with sea surface salinity. Marine Biology 151 (5), 1907-1915.

Hinrichsen, H. H., John, M. S., Lehmann, A., MacKenzie, B. R., Koster, F. W., 2002. Resolving the impact of short-term variations in physical processes impacting on the spawning environment of eastern Baltic cod: application of a 3-D hydrodynamic model. Journal of Marine Systems 32 (4), 281-294.

Hjort, J., 1914. Fluctuations in the great fisheries of northern europe viewed in the light of biological research. Rapp. P.-V. Reun. Cons. Int. Explor. Mer 20, 1-228. 
Huggett, J., Fréon, P., Mullon, C., Penven, P., 2003. Modelling the transport success of anchovy Engraulis encrasicolus eggs and larvae in the southern Benguela : the effect of spatio-temporal spawning patterns. Marine Ecology Progress Series 250, 247-262.

Huret, M., Runge, J. A., Chen, C. S., Cowles, G., Xu, Q. C., Pringle, J. M., 2007. Dispersal modeling of fish early life stages: sensitivity with application to Atlantic cod in the western Gulf of Maine. Marine Ecology Progress Series 347, 261-274.

Irigoien, X., Cotano, U., Boyra, G., Santos, M., Alvarez, P., Otheguy, P., Etxebeste, E., Uriarte, A., Ferrer, L., Ibaibarriaga, L., 2008. From egg to juvenile in the Bay of Biscay: spatial patterns of anchovy (Engraulis encrasicolus) recruitment in a non-upwelling region. Fisheries Oceanography 17 (6), 446-462.

Irigoien, X., Fiksen, O., Cotano, U., Uriarte, A., Alvarez, P., Arrizabalaga, H., Boyra, G., Santos, M., Sagarminaga, Y., Otheguy, P., Etxebeste, E., Zarauz, L., Artetxe, I., Motos, L., 2007. Could Biscay Bay anchovy recruit through a spatial loophole? Progress in Oceanography 74 (2-3), 132-148.

Kelly-Gerreyn, B. A., Hydes, D. J., Jegou, A. M., Lazure, P., Fernand, L. J., Puillat, I., Garcia-Soto, C., 2006. Low salinity intrusions in the western english channel. Continental Shelf Research 26 (11), 1241-1257.

Koutsikopoulos, C., Le Cann, B., 1996. Physical processes and hydrological structures related to the Bay of Biscay anchovy. Scientia Marina 60(2), 9-19. 
La Mesa, M., Donato, F., Giannetti, G., Arneri, E., 2009. Growth and mortality rates of European anchovy (Engraulis encrasicolus) in the Adriatic Sea during the transition from larval to juvenile stages. Fisheries Research 96, 275-280.

Langsrud, O., 2002. 50-50 multivariate analysis of variance for collinear responses. The Statistician 51 (3), 305-317.

Lazure, P., Dumas, F., 2008. An external-internal mode coupling for a 3D hydrodynamical Model for Applications at Regional Scale (MARS). Advances in Water Resources 31, 233-250.

Lazure, P., Garnier, V., Dumas, F., Herry, C., Chifflet, M., 2009. Development of a hydrodynamic model of the Bay of Biscay. validation of hydrology. Continental Shelf Research 29, 985-997.

Le Cann, B., 1990. Barotropic tidal dynamics of the Bay of Biscay shelf: observations, numerical modelling and physical interpretation. Continental Shelf Research 10 (8), 723-758.

Lett, C., Ayata, S., Huret, M., Irisson, J., Submitted. Biophysical modelling to investigate the effects of climate change on marine populations dispersal and connectivity. Progress in Oceanography, This issue.

Lett, C., Roy, C., Levasseur, A., van der Lingen, C. D., Mullon, C., 2006. Simulation and quantification of enrichment and retention processes in the southern Benguela upwelling ecosystem. Fisheries Oceanography 15 (5), 363-372. 
Lough, R., Buckley, L., Werner, F., Quinlan, J., Pehrson Edwards, K., 2005. A general biophysical model of larval cod (Gadus morhua) growth applied to populations on Georges Bank. Fisheries Oceanography 14 (4), 241-262.

Lough, R., Hannah, C., Berrien, P., Brickman, D., Loder, J., Quinlan, J., 2006. Spawning pattern variability and its effect on retention, larval growth and recruitment in Georges Bank cod and haddock. Marine Ecology Progress Series 310, 193-212.

Lyard, F., Lefevre, F., Letellier, T., Francis, O., 2006. Modelling the global ocean tides: modern insights from FES2004. Ocean Dynamics 56 (5-6), 394-415.

Miller, T. J., 2007. Contribution of individual-based coupled physicalbiological models to understanding recruitment in marine fish populations. Marine Ecology Progress Series 347, 127-138.

Motos, L., Uriarte, A., Valencia, V., 1996. The spawning environment of the Bay of Biscay anchovy (Engraulis encrasicolus 1.). Scientia Marina 60, $117-140$.

Nathan, R., Muller-Landau, H. C., 2000. Spatial patterns of seed dispersal, their determinants and consequences for recruitment. Trends In Ecology \& Evolution 15 (7), 278-285.

North, E. W., Schlag, Z., Hood, R. R., Li, M., Zhong, L., Gross, T., Kennedy, V. S., 2008. Vertical swimming behavior influences the dispersal of simulated oyster larvae in a coupled particle-tracking and hydrodynamic model of Chesapeake Bay. Marine Ecology Progress Series 359, 99-115. 
Parada, C., Mullon, C., Roy, C., Fréon, P., Hutchings, L., van der Lingen, C. D., Dec. 2008. Does vertical migratory behaviour retain fish larvae onshore in upwelling ecosystems? A modelling study of anchovy in the southern Benguela. African Journal of Marine Science 30 (3), 437-452.

Pineda, J., Hare, J. A., Sponaugle, S., 2007. Larval transport and dispersal in the coastal ocean and consequences for population connectivity. Oceanography 20 (3), 22-39.

Pingree, R., Le Cann, B., 1989. Celtic and Armorican slope and residual currents. Progress in Oceanography 23, 303-338.

Pingree, R. D., Le Cann, B., 1990. Structure, strength and seasonality of the slope currents in the Bay of Biscay region. Journal of the Marine Biological Association of the United Kingdom 70, 107-128.

Pingree, R. D., Le Cann, B., 1992. Three anticyclonic Slope Water Oceanic eDDIES (SWODDIES) in the southern Bay of Biscay in 1990. Deep-Sea Research 39 (7/8), 1147-1175.

Puillat, I., Lazure, P., Jegou, A. M., Lampert, L., Miller, P. I., 2004. Hydrographical variability on the French continental shelf in the Bay of Biscay, during the 1990's. Continental Shelf Research 24, 1143-1163.

Ré, P., 1996. Anchovy spawning in the Mira estuary (southwestern Portugal). Scientia Marina 60 (2), 141-153.

Reynaud, T., Legrand, P., Mercier, H., Barnier, B., 1998. A new analysis of hydrographic data in the Atlantic and its application to an inverse modelling study. Int. WOCE Newsletter 32, 29-31. 
Ross, O., Sharples, J., 2004. Recipe for 1-D Lagrangian tracking models in space-varying diffusivity. Limnology Oceanography: Methods 2, 289-302.

Serpette, A., Le Cann, B., Colas, F., 2006. Lagrangian circulation of the North Atlantic Central Water over the abyssal plain and continental slopes of the Bay of Biscay: description of selected mesoscale features. Scientia Marina 70, 27-42.

Siegel, D., Kinlan, B., Gaylord, B., Gaines, S., 2003. Lagrangian descriptions of marine larval dispersion. Marine Ecology Progress Series 260, 83-96.

Sinclair, M., 1988. Marine populations : an essay on population regulation and speciation. Washington University Press, Seattle, WA, 252 p.

Svendsen, E., Skogen, M., Budgell, P., Huse, G., Stiansen, J. E., Adlandsvik, B., Vikebo, F., Asplin, L., Sundby, S., 2007. An ecosystem modeling approach to predicting cod recruitment. Deep-Sea Research Part II-Topical Studies in Oceanography 54 (23-26), 2810-2821.

Visser, A., 1997. Using random walk models to simulate the vertical distribution of particles in a turbulent water column. Marine Ecology Progress Series 158, 275-281.

Werner, F., Quinlan, J., Blanton, B., Luettich Jr., R., 1997. The role of hydrodynamics in explaining variability in fish populations. Journal of Sea Research 37, 195-212.

Werner, F., Quinlan, J., Lough, R., Lynch, D., 2001. Spatially-explicit individual based modeling of marine populations : a review of the advances in the 1990s. Sarsia 86, 411-421. 
Werner, F. E., Cowen, R. K., Paris, C. B., 2007. Coupled biological and physical models present capabilities and necessary developments for future studies of population connectivity. Oceanography 20 (3), 54-69.

Woillez, M., Poulard, J.-C., Rivoirard, J., Petitgas, P., Bez, N., 2007. Indices for capturing spatial patterns and their evolution in time, with application to European hake (Merluccius merluccius) in the Bay of Biscay. ICES Journal of Marine Science 64, 537-550.

Woillez, M., Rivoirard, J., Petitgas, P., 2009. Notes on survey-based spatial indicators for monitoring fish populations. Aquatic Living Resources $22(2), 155-164$. 


\section{List of Figures}

1 Trajectories of buoys (WOCE/SVP type, Technocean, Florida, USA) drogued at $15 \mathrm{~m}$ depth over a 2 months period. Release locations are marked with crossed circle $\left(45.18^{\circ} \mathrm{N}-2.00^{\circ} \mathrm{W}\right.$ for buoys 78581 and 78594 , and $45.33^{\circ} \mathrm{N}-01.39^{\circ} \mathrm{W}$ for buoys 78583 and 78595$)$. Buoys 78581 and 78583 (grey) are released on April $20^{\text {th }}$ and $21^{\text {th }}$ respectively. Buoys 78594 and 78595 (black) are released on June $5^{\text {th }}$. Circles from 1 to 5 are selected release locations for the particle tracking experiments. . . . . . 41

2 Projection of all kernels on the factorial plan of a Principal Component Analysis (PCA) computed on indices (except geographic positions) from all experiments (left panel). The first two PCA explain $60 \%$ of the variance. Individuals are grouped by behaviour classes : 1: fix depth (black dots), 2: random walk (dark grey dots), 3: behaviour (light grey dots). Right panel is the correlation circle of indices with the principal axis of the PCA. Max. axis label overlaps Min. axis and Inertia. . . . . . . . . 4

3 Distribution of particles after a 50 days drift period from a release on June $3^{\text {rd }} 2001$ at spawning location 3 (white filled circle offshore the Gironde estuary) under the three vertical behaviours : fix depth (black dots), random walk (dark grey dots) and vertical migration (light grey dots). . . . . . . . . . . . . . . . 43 
4 Box plots and means of selected indices describing dispersal for different larval drift durations. The box stretches from the lower hinge (defined as the 25th percentile or the first quartile Q1) to the upper hinge (defined as the 75th percentile or the third quartile Q3). The median is shown as a line across the box. The means are linked by a line over the different durations. The whiskers extend to the farthest points that are not outliers (i.e. that are within 3/2 times the range between quartiles Q1 and Q3). Statistics are computed for the 5 spawning locations and for the 18 release dates of each year over the period 1996-2007. Model configuration is vertical swimming behaviour. . . . . . . . . . . . . . . . . . 44

5 Box plots and means of selected indices describing dispersal from the 5 discrete spawning locations. Extreme values defined as outliers are represented by dots. Statistics are computed from the 18 release dates of each year over the period 1996-2007. Larval drift duration is fixed at 50 days and model configuration is vertical swimming behaviour. . . .

6 Principal axis from a Principal Component Analysis on the position of the Centres of Gravity (CG) of kernels for each spawning location and a larval drift duration of 50 days. Statistics are computed on CGs from the 18 release dates of each year over the period 1996-2007. Dashed lines are the mean trajectories of CGs, connecting centres of each spawning locations, which areas are represented by circles, to the mean CG at the end of the drift period. . . . . . . . . . . . . . . . . . 46 46 
$7 \quad$ Mean drift direction per release date and from the 5 spawning areas. Arrows head are the mean position per release date of Centres of Gravity (CG) of every years over the period 1996-2007. Arrows turn from black to light grey as the season progresses. . . . . . . . . . . . . . . . . . 47

8 Box plots and means of selected indices describing dispersal for successive releases from spawning location 3 offshore the Gironde estuary. Horizontal line on right plot indicates latitude of the spawning location. Statistics are computed for the 18 release dates of each year over the period 19962007. Larval drift duration is fixed at 50 days and model configuration is vertical swimming behaviour. . . . . . . . . . . . . . . . . . . . . 48

9 Projections of the dispersal kernels on the principal Multiple Factorial Analysis (MFA) plane (left panels) for spawning locations 1 (south, bottom) to 5 (north, top). Numbers represent the centre of gravity of each group defined by their release week (only weeks with odd numbers are plotted). Each group contains the 12 years from 1996 to 2007, represented as dots linked to their respective release date. Inertia among years for each release date (right panels). The inertia for each group of release dates is the annual squared distance to the centre of gravity summed over the years. . . . . . . . . . . . . . . . . . . . . . . 49

10 Particle distribution for releases on April $1^{\text {st }} 2001$ for spawning location 5 and on July $28^{\text {th }} 2005$ from spawning location 1. Release locations are identified by circle areas next to the dates. . . . . . . . . . . . . . . 50 


\section{List of Tables}

1 Full experiment plan of the study with all tested factors on the dispersal kernels characterised by the listed 13 indices. See Fig. 6 for correspondence of locations. . . . . . . . . . . . . . . . . 38

2 Results of a MANOVA on 5 sets of response variables: (i) geographic position of the Centre of Gravity (CG) of the distribution of particles, (ii) relative position of the CG (distance and direction from the release location), (iii) parameters of the variance of the distribution (ellipse), (iv) parameters related to space occupation and aggregation (aggregation), and (v) the whole set of parameters (all). Values are percentages representing the amount of variance in one set of response variable that is explained by each factor. All primary factors and any second-order interaction effects $>1.0 \%$ are included. . . . . . . . . . . . . 39

3 Summary of correlations between indices and the first two Multiple Factorial Analysis (MFA) factorial axis: - correlation $<-0.5 ;+$ correlation $>0.5$. A separate MFA is performed for each of the release location for a larval drift duration of 50d. The numbers indicate the number of years for which $\mathrm{a}+$ or - correlation is observed. Total number of years is 12 . Numbers are indicated only if the number of years with + or correlation is $>6$. This is never the cas for location 4. . . . . . . . . . 40 


\begin{tabular}{|c|c|c|c|c|c|}
\hline \multicolumn{5}{|c|}{ Factors } & \multirow[t]{2}{*}{ Indices } \\
\hline Location & Year & Week & Behaviour & Duration & \\
\hline \multirow[t]{3}{*}{1} & 1996 & April $1^{s t}$ & & & Longitude of CG \\
\hline & 1997 & April $8^{t h}$ & Fix depth & 20 days & Latitude of CG \\
\hline & $\mid$ & $\mid$ & & & Inertia \\
\hline \multirow[t]{3}{*}{2} & $\mid$ & | & & 30 days & Min. Axis \\
\hline & $\mid$ & $\mid$ & & & Max. Axis \\
\hline & $\mid$ & $\mid$ & & 40 days & Isotropy \\
\hline \multirow[t]{3}{*}{3} & $\mid$ & every week & Random walk & & Orientation \\
\hline & $\mid$ & & & 50 days & Distance \\
\hline & $\mid$ & | & & & Direction \\
\hline \multirow[t]{3}{*}{4} & $\mid$ & $\mid$ & & 60 days & Positive area \\
\hline & $\mid$ & $\mid$ & Vertical swimming & & Equivalent area \\
\hline & 2006 & July $22^{t h}$ & + Random Walk & 70 days & Spreading area \\
\hline 5 & 2007 & July $29^{t h}$ & & & Coefficient of Variation \\
\hline
\end{tabular}

Table 1: Full experiment plan of the study with all tested factors on the dispersal kernels characterised by the listed 13 indices. See Fig. 1 for correspondence of locations. 


\begin{tabular}{lc|ccccc}
\hline Factor & df & $\begin{array}{c}\text { Geographic } \\
\text { position }\end{array}$ & $\begin{array}{c}\text { Relative } \\
\text { position }\end{array}$ & Ellipse & Aggregation & all \\
\hline Location & 4 & 62.4 & 23.3 & 8.6 & 1.7 & 17.0 \\
Year & 11 & 2.0 & 4.4 & 2.9 & 0.7 & 2.3 \\
Week & 17 & 0.8 & 2.7 & 1.2 & 0.3 & 1.1 \\
Behaviour & 2 & 0.5 & 0.9 & 4.3 & 55.4 & 18.9 \\
Duration & 5 & 2.0 & 6.0 & 19.9 & 11.0 & 12.3 \\
Location x Year & 44 & 6.4 & 9.1 & 5.9 & 1.4 & 5.1 \\
Location x Week & 68 & 5.4 & 5.4 & 3.5 & 0.6 & 3.2 \\
Location x Behaviour & 8 & 1.1 & 1.4 & 0.6 & 3.0 & 1.5 \\
Location x duration & 20 & 1.8 & 1.2 & 1.4 & 0.1 & 1.0 \\
Year x Week & 187 & 2.7 & 6.5 & 3.2 & 1.2 & 3.0 \\
Behaviour x duration & 10 & 0.1 & 0.0 & 0.4 & 5.9 & 2.0 \\
\hline Others & & 0.8 & 1.6 & 2.0 & 0.7 & 1.4 \\
Residuals & 18867 & 14.0 & 37.5 & 46.1 & 18.0 & 31.2 \\
\hline
\end{tabular}

Table 2: Results of a MANOVA on 5 sets of response variables: (i) geographic position of the Centre of Gravity (CG) of the distribution of particles, (ii) relative position of the CG (distance and direction from the release location), (iii) parameters of the variance of the distribution (ellipse), (iv) parameters related to space occupation and aggregation (aggregation), and (v) the whole set of parameters (all). Values are percentages representing the amount of variance in one set of response variable that is explained by each factor. All primary factors and any second-order interaction effects $>1.0 \%$ are included. 


\begin{tabular}{|c|c|c|c|c|c|c|c|c|}
\hline \multirow[t]{2}{*}{ Indices } & \multicolumn{2}{|c|}{ Location 1} & \multicolumn{2}{|c|}{ Location 2} & \multicolumn{2}{|c|}{ Location 3} & \multicolumn{2}{|c|}{ Location 5} \\
\hline & Axis 1 & Axis 2 & Axis 1 & Axis 2 & Axis 1 & Axis 2 & Axis 1 & Axis 2 \\
\hline Inertia & +7 & & & & +9 & & & \\
\hline Min Axis & +6 & & & & +8 & & -6 & \\
\hline Max Axis & +7 & & & -6 & +9 & & & \\
\hline Isotropy & & & & & & & -6 & \\
\hline Orientation & & & & & & & & \\
\hline Distance & +8 & & & & & & -6 & \\
\hline Direction & +8 & & & & +7 & & +11 & \\
\hline Positive area & +10 & & +7 & & +8 & & -7 & \\
\hline Equivalent area & & & & & & & -6 & \\
\hline Spreading area & +6 & & +7 & & +6 & & -7 & \\
\hline Coefficient of Variation & & & & & & & & \\
\hline
\end{tabular}

Table 3: Summary of correlations between indices and the first two Multiple Factorial Analysis (MFA) factorial axis: - correlation $<-0.5 ;+$ correlation $>0.5$. A separate MFA is performed for each of the release location for a larval drift duration of $50 \mathrm{~d}$. The numbers indicate the number of years for which a + or - correlation is observed. Total number of years is 12 . Numbers are indicated only if the number of years with + or - correlation is $>6$. This is never the cas for location 4 . 


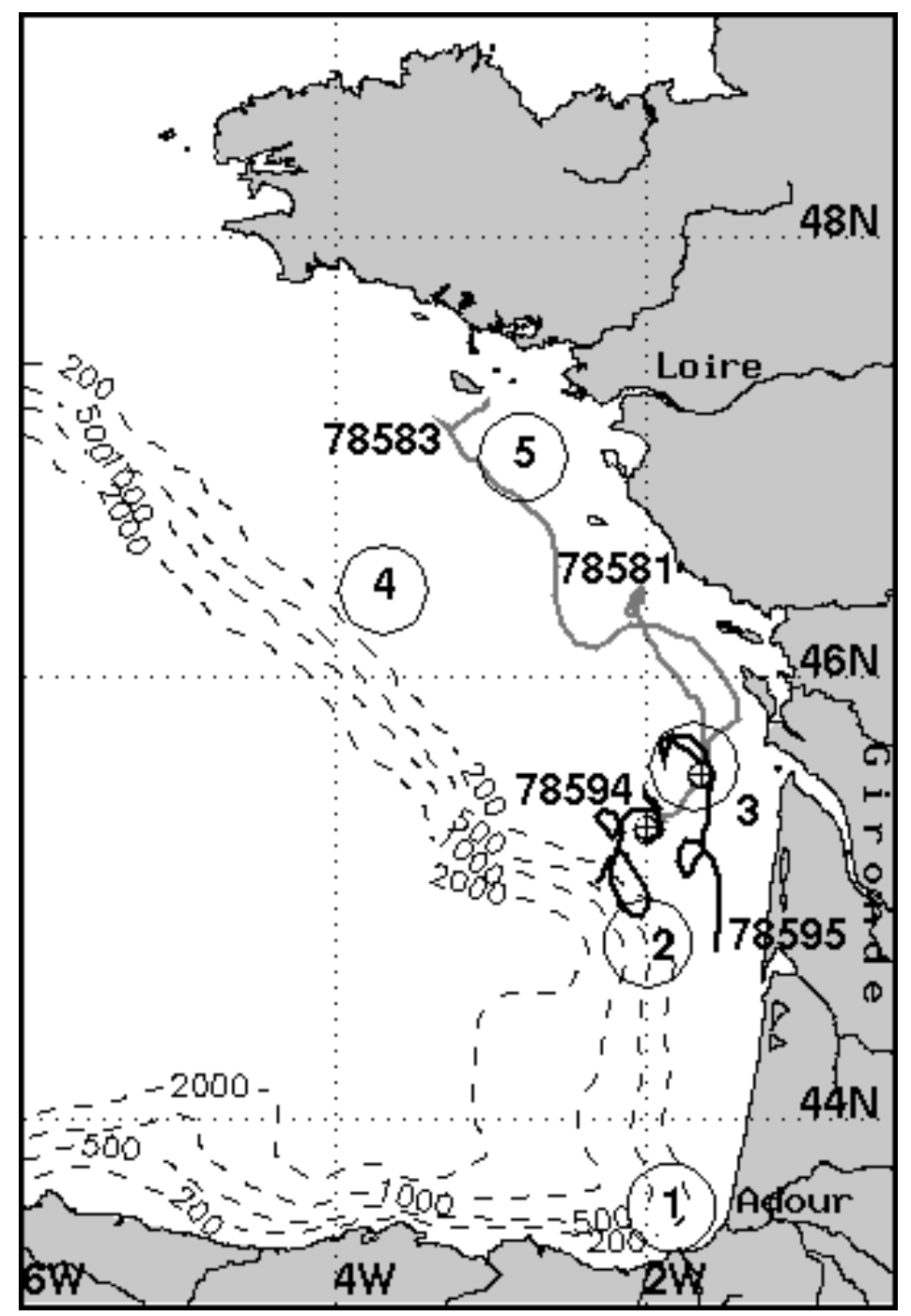

Figure 1: Trajectories of buoys (WOCE/SVP type, Technocean, Florida, USA) drogued at $15 \mathrm{~m}$ depth over a 2 months period. Release locations are marked with crossed circle $\left(45.18^{\circ} \mathrm{N}-2.00^{\circ} \mathrm{W}\right.$ for buoys 78581 and 78594 , and $45.33^{\circ} \mathrm{N}-01.39^{\circ} \mathrm{W}$ for buoys 78583 and 78595). Buoys 78581 and 78583 (grey) are released on April $20^{\text {th }}$ and $21^{\text {th }}$ respectively. Buoys 78594 and 78595 (black) are released on June $5^{\text {th }}$. Circles from 1 to 5 are selected release locations for the particle tracking experiments. 


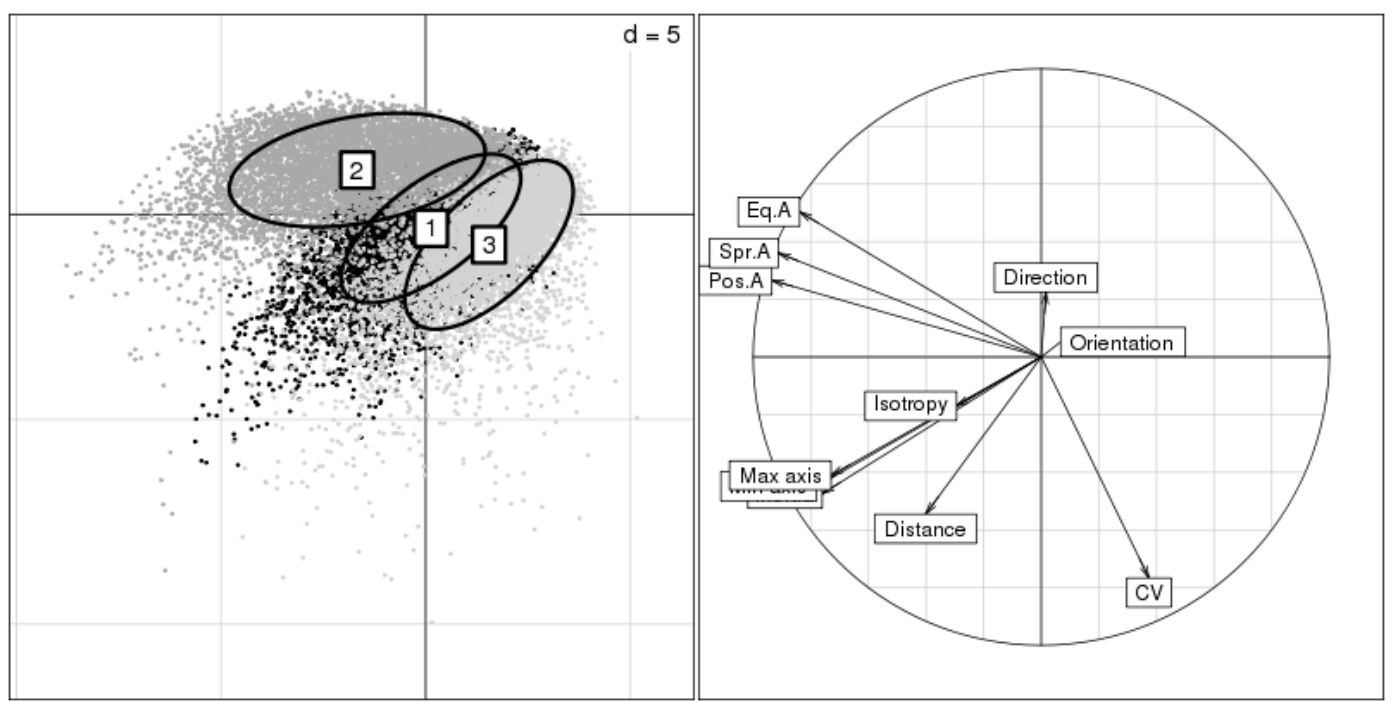

Figure 2: Projection of all kernels on the factorial plan of a Principal Component Analysis (PCA) computed on indices (except geographic positions) from all experiments (left panel). The first two PCA explain $60 \%$ of the variance. Individuals are grouped by behaviour classes : 1: fix depth (black dots), 2: random walk (dark grey dots), 3: behaviour (light grey dots). Right panel is the correlation circle of indices with the principal axis of the PCA. Max. axis label overlaps Min. axis and Inertia. 


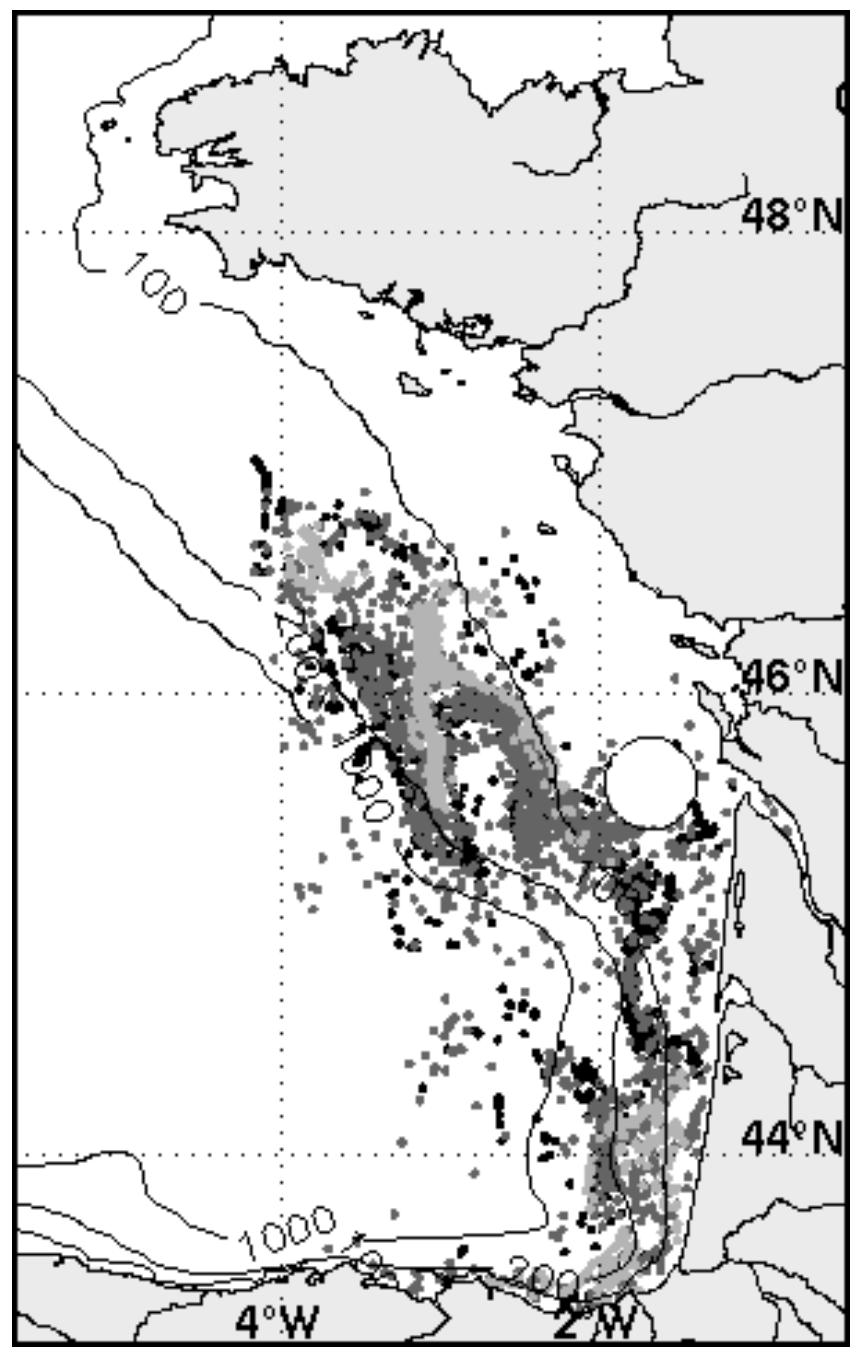

Figure 3: Distribution of particles after a 50 days drift period from a release on June $3^{\text {rd }} 2001$ at spawning location 3 (white filled circle offshore the Gironde estuary) under the three vertical behaviours : fix depth (black dots), random walk (dark grey dots) and vertical migration (light grey dots). 

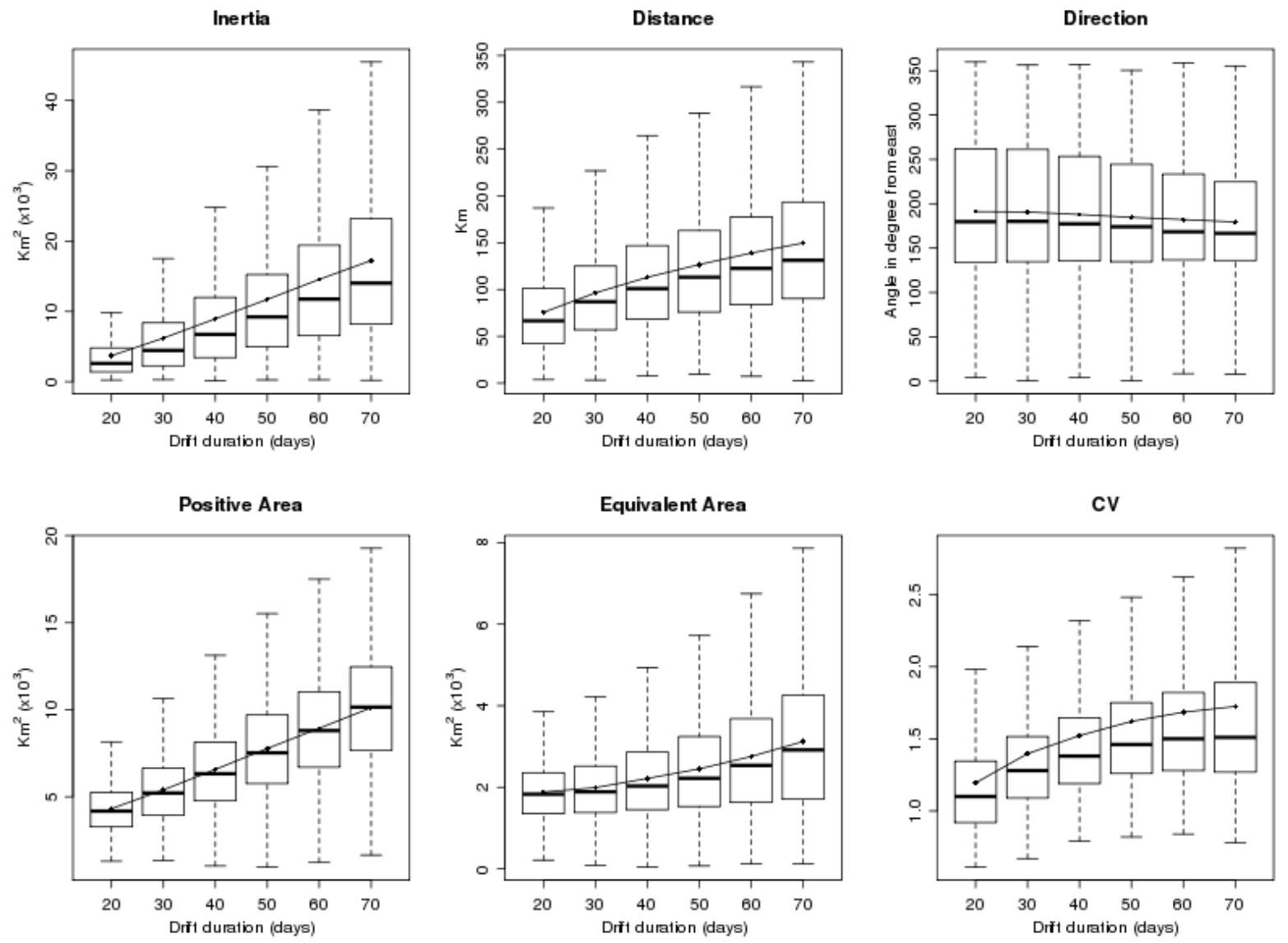

Figure 4: Box plots and means of selected indices describing dispersal for different larval drift durations. The box stretches from the lower hinge (defined as the 25th percentile or the first quartile Q1) to the upper hinge (defined as the 75th percentile or the third quartile Q3). The median is shown as a line across the box. The means are linked by a line over the different durations. The whiskers extend to the farthest points that are not outliers (i.e. that are within 3/2 times the range between quartiles Q1 and Q3). Statistics are computed for the 5 spawning locations and for the 18 release dates of each year over the period 1996-2007. Model configuration is vertical swimming behaviour. 

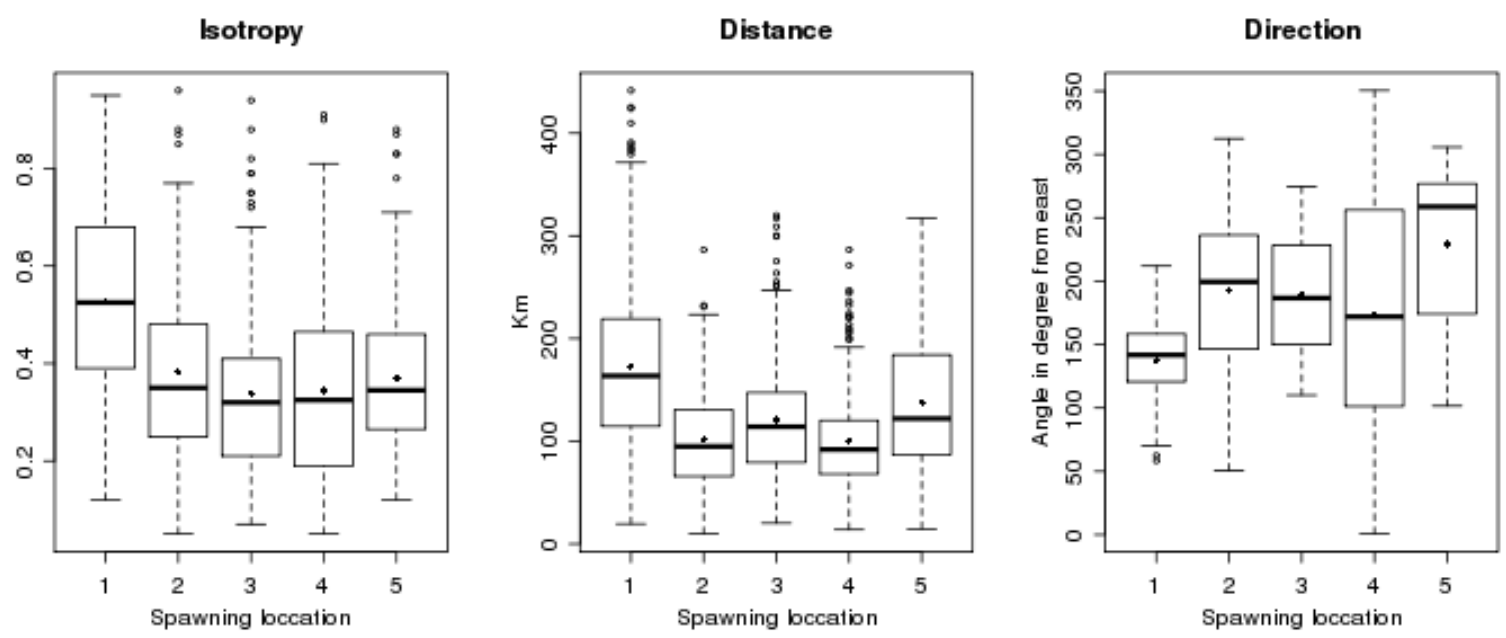

Figure 5: Box plots and means of selected indices describing dispersal from the 5 discrete spawning locations. Extreme values defined as outliers are represented by dots. Statistics are computed from the 18 release dates of each year over the period 1996-2007. Larval drift duration is fixed at 50 days and model configuration is vertical swimming behaviour. 


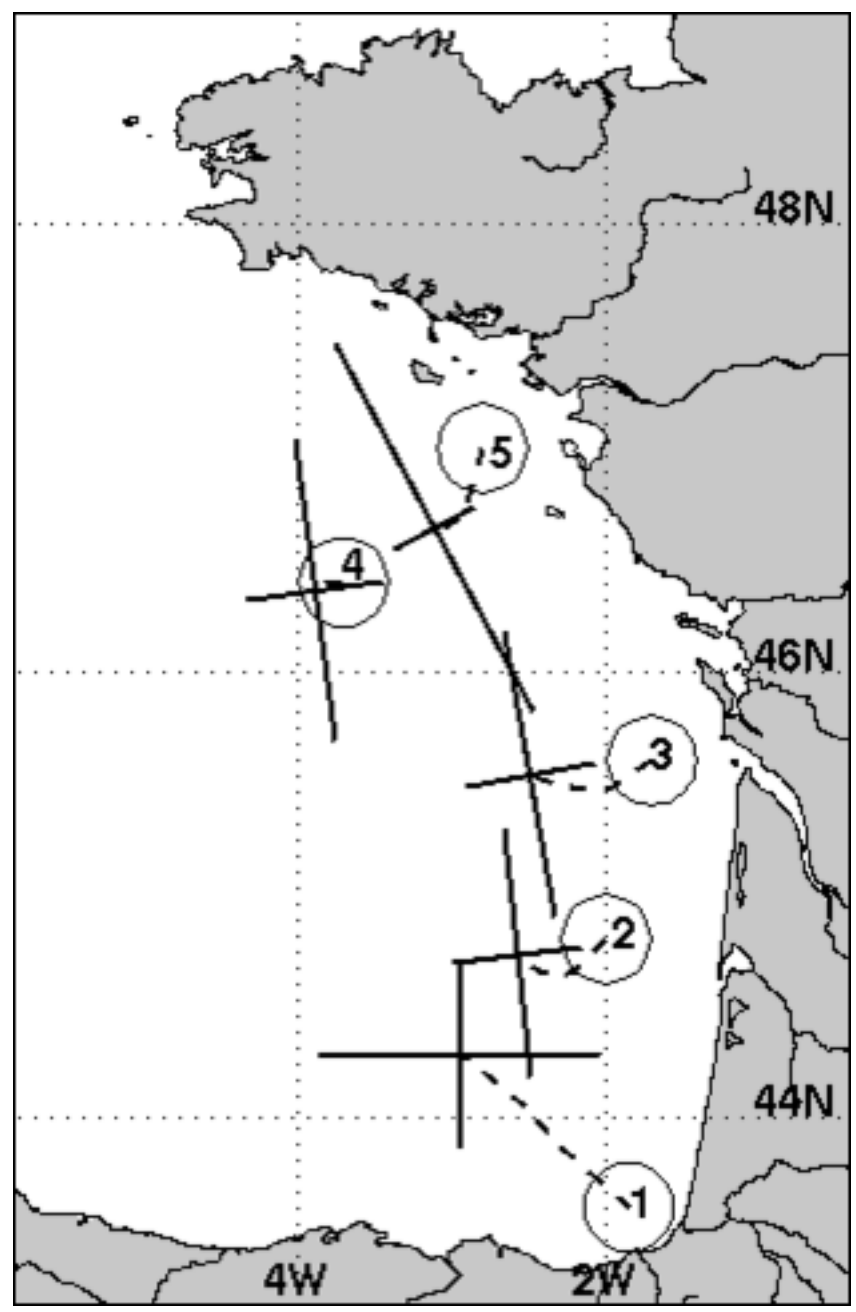

Figure 6: Principal axis from a Principal Component Analysis on the position of the Centres of Gravity (CG) of kernels for each spawning location and a larval drift duration of 50 days. Statistics are computed on CGs from the 18 release dates of each year over the period 1996-2007. Dashed lines are the mean trajectories of CGs, connecting centres of each spawning locations, which areas are represented by circles, to the mean CG at the end of the drift period. 


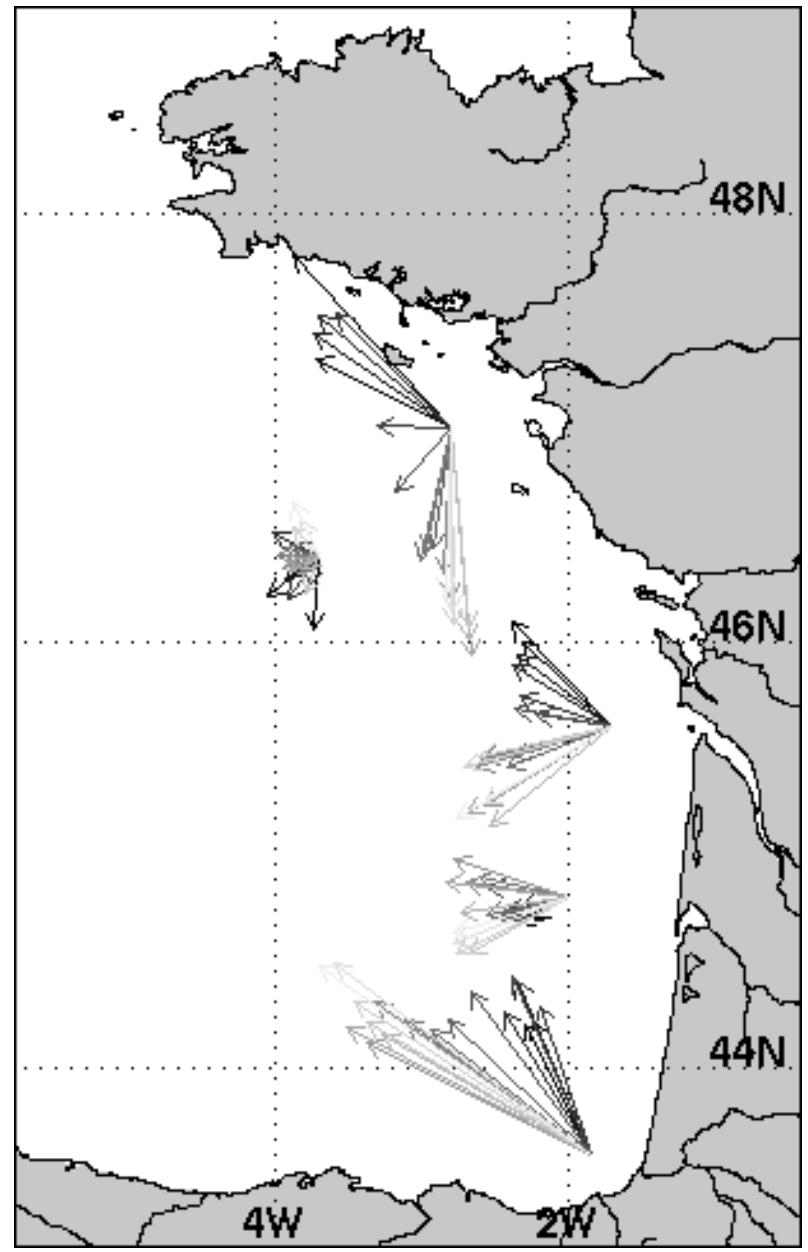

Figure 7: Mean drift direction per release date and from the 5 spawning areas. Arrows head are the mean position per release date of Centres of Gravity (CG) of every years over the period 1996-2007. Arrows turn from black to light grey as the season progresses. 

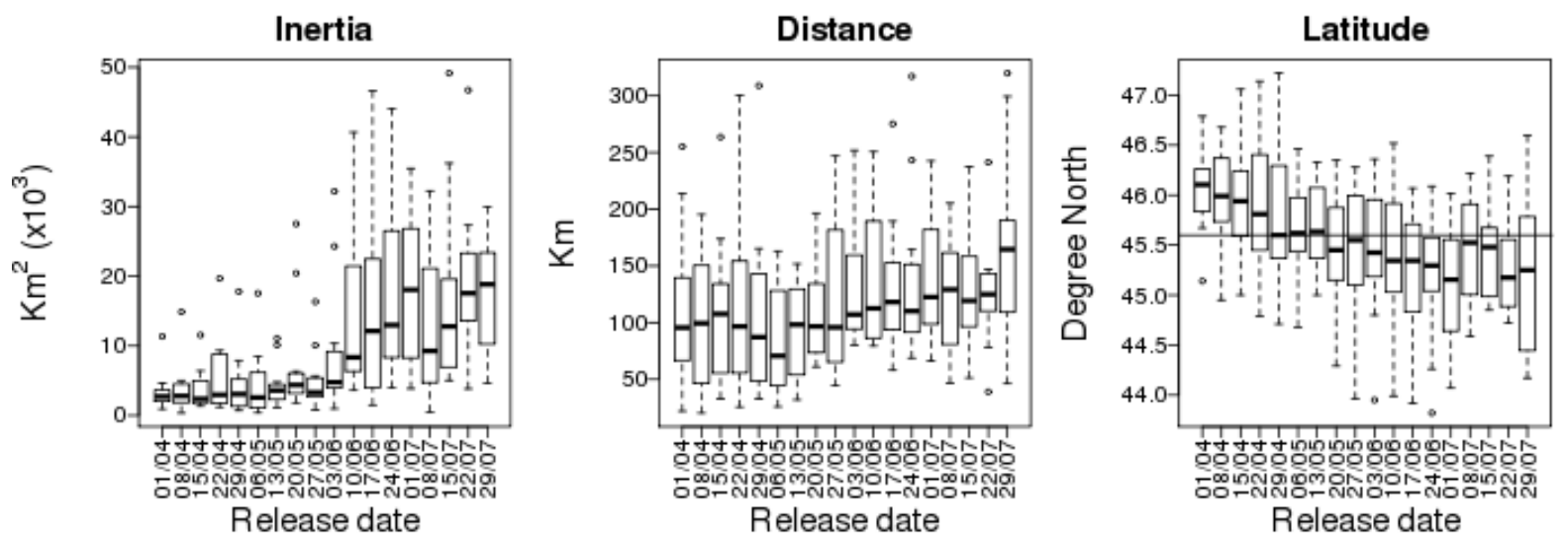

Figure 8: Box plots and means of selected indices describing dispersal for successive releases from spawning location 3 offshore the Gironde estuary. Horizontal line on right plot indicates latitude of the spawning location. Statistics are computed for the 18 release dates of each year over the period 1996-2007. Larval drift duration is fixed at 50 days and model configuration is vertical swimming behaviour. 

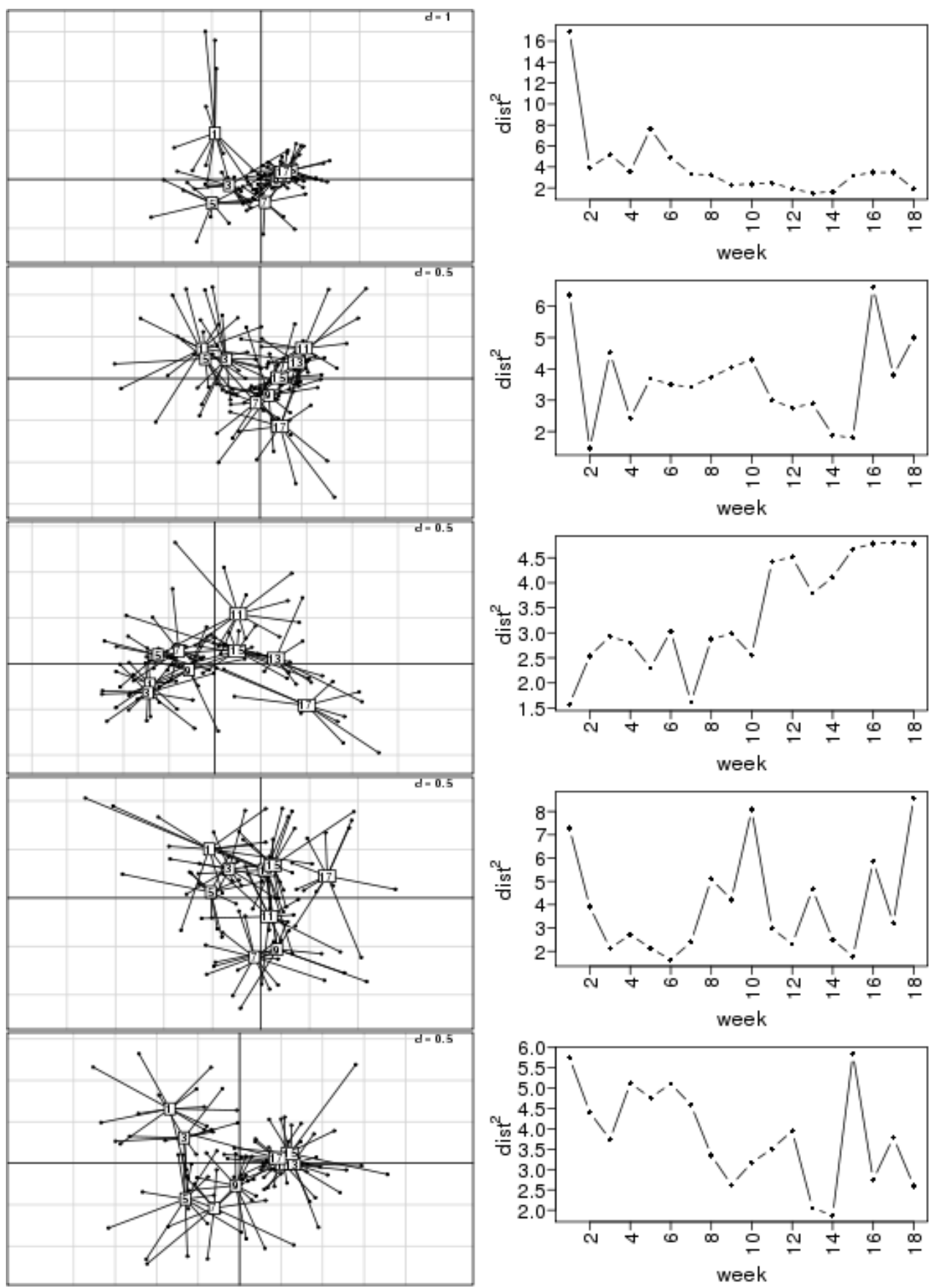

Figure 9: Projections of the dispersal kernels on the principal Multiple Factorial Analysis (MFA) plane (left panels) for spawning locations 1 (south, bottom) to 5 (north, top). Numbers represent the centre of gravity of each group defined by their release week (only weeks with odd numbers are plotted). Each group contains the 12 years from 1996 to 2007, represented as dots linked to their respective release date. Inertia among years for each release date (right panels). The inertia for each group of release dates is the annual squared distance to the centre of gravity summed over the years. 


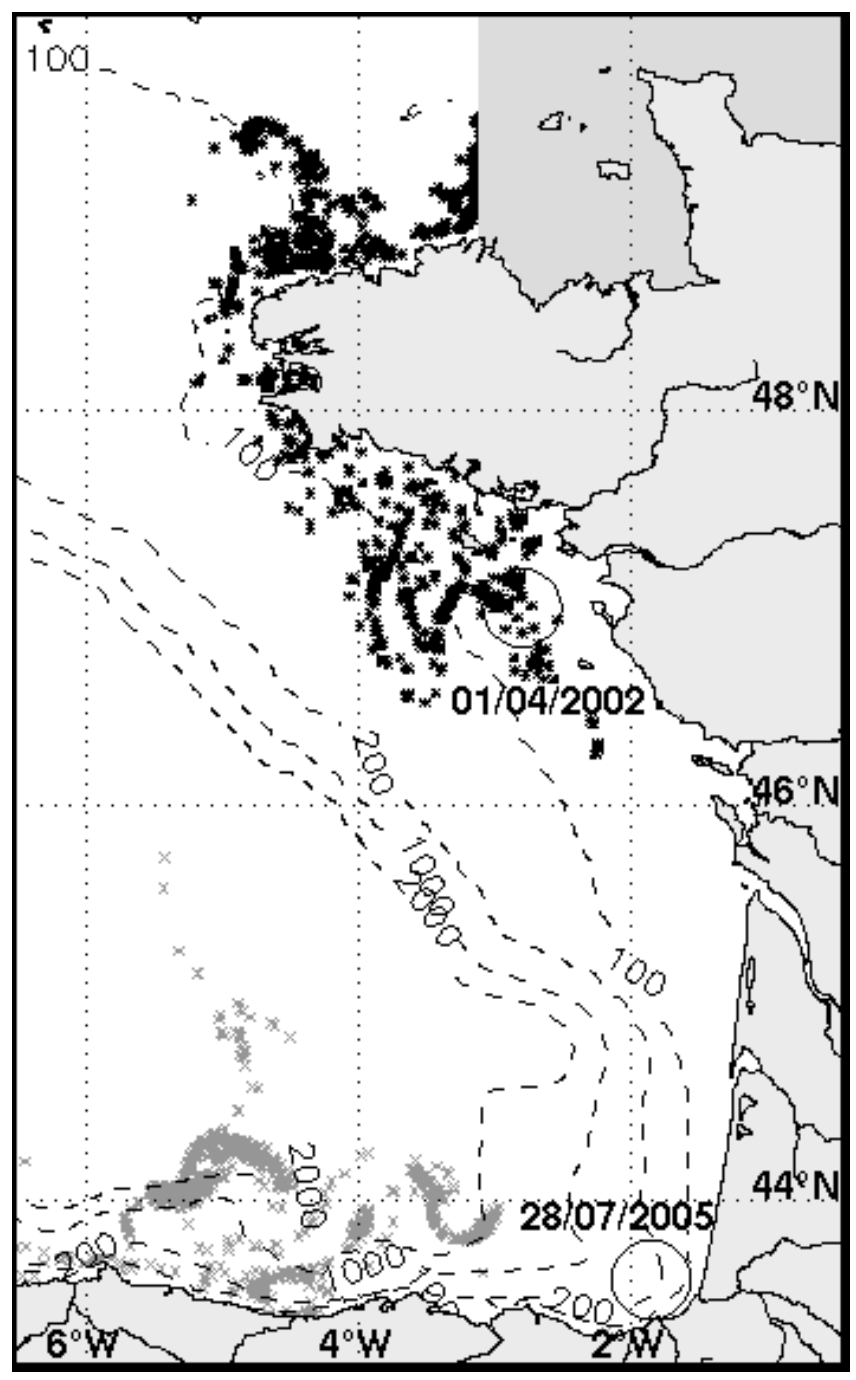

Figure 10: Particle distribution for releases on April $1^{\text {st }} 2001$ for spawning location 5 and on July $28^{t h} 2005$ from spawning location 1 . Release locations are identified by circle areas next to the dates. 